\title{
ВЫДЕЛЕНИЕ СОВРЕМЕННОГО ГОРОДСКОГО ЦЕНТРА В НАБЕРЕЖНЫХ ЧЕЛНАХ: ВЗГЛЯД ГОРОЖАН
}

\section{Гильмутдинова Лия Рафисовна \\ студент \\ НИУ «Высшая школа экономики»}

Аннотация: $\mathrm{XX}$ век - век массового возникновения новых индустриальных городов, которые были спланированы лишь с одной целью дать нуждающейся молодой стране специализированное производство. Это так называемые моногорода, которые в настоящий момент переживают сильнейший внутренний кризис. Однако, это не только экономический кризис, который все привыкли обсуждать, но и кризис единого, целостного территориального развития, выражающийся в том, что ответить на вроде бы простой вопрос «где в Набережных Челнах расположен центр города?» большая трудность даже для местных жителей. Результатом данной работы будет попытка выделения актуальных границ центра города на основе анализа глубинных интервью с местными жителями.

Ключевые слова: городской центр, вернакулярный район, моногород, метод глубинного интервью, линейный город

\section{HIGHLIGHTING THE MODERN URBAN CENTER IN NABEREZHNYE CHELNY: THE VIEW OF THE CITIZENS}

\section{Gilmutdinova Liya Rafisovna}

Abstract: The twentieth century is the century of the mass emergence of new industrial cities, which were planned for only one purpose - to give a young country in need specialized production. These are the so-called single-industry towns that are currently experiencing a severe internal crisis. However, this is not only an economic crisis that everyone is used to discussing, but also a crisis of a single, integral territorial development, expressed in the fact that the answer to the seemingly simple question "where is the city center located in Naberezhnye Chelny?" - a big difficulty even for the locals. The result of this work will be an attempt to highlight the actual boundaries of the city center based on the analysis of in-depth interviews with local residents. 


\section{ВСЕРОССИЙСКИЙ ИССЛЕДОВАТЕЛЬСКИЙ ФОРУМ

Key words: urban center, vernacular district, monotown, in-depth interview method, linear city

\section{Особенности развития моногородов}

Моногород - это муниципальное образование, определяющим фактором развития которого является предприятия градообразующего комплекса ${ }^{1}$ [Маслова, 16]. Согласно статистическим данным Института комплексных стратегических исследований (ИКСИ) за 2017 год 9\% россиян проживают в моногородах, а в некоторых регионах процент населения моногородов достигает $20 \%{ }^{2}$. Моногорода нельзя отделить от градообразующего предприятия - они неразрывно связаны друг с другом, образуя сложную структуру [Ильина,11]. Зарубежные исследователи выделили несколько признаков, согласно которым поселение можно классифицировать как моногород: 1) функционирование одного или нескольких однотипных предприятий, относящихся к одной отрасли или обслуживающих один узкий сегмент отраслевого рынка; 2) наличие цепочки технологически связанных предприятий, работающих на один конечный рынок; 3) значительная зависимость доходной части бюджета города от деятельности одного или нескольких крупных предприятий; 4) подчинение городской планировки особенностям производственной деятельности основного предприятия; 5) высокие риски экологического загрязнения; 6) простая структура занятости населения; 7) слабый уровень диверсификации экономики города [Ильина, 9-10]

Ученые выделяют три формы специализации моногорода: 1) монофункциональный (содержит ограниченное число предприятий, которые обеспечивают ему экономическую устойчивость); 2) моноотраслевой (несколько предприятий градообразующей области); 3) моноцентрический (функционирует только одно предприятие). Таким образом, Набережные Челны относятся к моноцентрическому типу городов.

Российские моногорода получили свои будущие экономические, территориальные и социальные проблемы в основном в период ускоренной советской индустриализации, когда города становились точкой концентрации и

\footnotetext{
1 Градообразующий комплекс - одно или несколько предприятий одной отрасли либо смежных отраслей, связанных единой технологической цепочкой, которые в сумме производят не менее 50\% валового продукта города, либо на которых работает не менее 25\% экономически активного населения города [Маслова, 16].

${ }^{2}$ Обзор российских моногородов: https://icss.ru/vokrug-statistiki/obzor-rossijskix-monogorodov
} 


\section{ВСЕРОССИЙСКИЙ ИССЛЕДОВАТЕЛЬСКИЙ ФОРУМ СТУДЕНТОВ И УЧАЩИХСЯ}

специализации одной промышленной области [Ильина, 4].

\section{К вопросу о морфологии городского центра}

В России первое исследование, посвященное проблеме целостности городского центра, появилось только в 2016 году. Так, в работе центр города был определен как специфичный городской феномен, который соединят в единое целое социальное и визуальное пространство города [Гашенко,83]. Проблема городской визуальной целостности четко выявляется при выделении городского центра: интуитивно центр в городе всегда наличествует, однако возникают трудности при попытках вывести типичные черты, которые будут присущи всем городским центрам. В определенном типе городов возможность однозначно выделить центр как таковой не представляется - это города с рыхлой или политипологической структурой центра, примером такого города может послужить Новосибирск [Гашенко, 83]. Определения городского центра в зависимости от выбранного аспекта могут быть следующими:

Вернакулярный внутригородской район, который в сознании жителей находится в оппозиции к периферии. Центр в качестве вернакулярного района как правило имеет самую большую территорию, особенно если это вернакулярный район с точки зрения горожан со срединных и периферийных районов [Бегеза 2014, 84]

Узкопрофессиональный модельный конструкт урбанистов (архитекторов, градостроителей), трактующих центр в качестве ареала концентрации социальной активности и общественных функций. Узкопрофессиональный, «урбанистический» центр выделяется на основе социально-функциональных процессов, протекающих на территории. Здесь центр представляется каркасноузловой структурой, которая тяготеет к улицам и площадям с наибольшей активностью.

Как видимое (архитектурно-средовое) проявление лучших культурных образцов городского пространства. Более традиционная точка зрения на центр заключается в выделении композиционно-ансамблевой структуры территории. Центр - проявление лучших, «кристаллизованных» объектов архитектурноградостроительной культуры.

Все три определения центров не сопоставляются друг с другом по смыслу.

\section{Набережные Челны: о контексте}




\section{ВСЕРОССИЙСКИЙ ИССЛЕДОВАТЕЛЬСКИЙ ФОРУМ

Набережные Челны - яркий пример «идеального социалистического города», в представлениях советских проектировщиков 70-х годов. В функционально-планировочной структуре, архитектурно-градостроительной организации почти идеально воплощены в жизнь градостроительные концепции первой половины двадцатого века, такие как модель линейного города Н.Милютина(1930г.), концепция жесткого функционального зонирования и микрорайонная застройка [Дембич, Закирова: 2020].

В Генеральном плане Набережных Челнов изначально не заложено центральное общественное ядро. Весь город представляет из себя монотонную жилую застройку панельного типа. Вокруг стихийно образовавшихся торговых зон формируются городские субцентры. Другая особенность планировки Челнов состоит в том, что основной единицей планировочной структуры является укрупнённый микрорайон, или «межмагистральная жилая территория» - сокращённо ММТ. Это была распространившейся после первой пробы в Тольятти практика СССР по внедрению наиболее экономичной организации селитебных территорий в крупных городах. Такой формат планировочной структуры существенно экономил протяжённость уличнодорожных и инженерных сетей и при этом сохранял идею «бестранспортного» внутреннего пространства жилой среды города: [Дембич, Закирова: 2020].

Также, в генеральный план Набережных Челнов заложены следующие ключевые идеи:

• линейный город с четким полосовым функциональным зонированием;

- укрупненный микрорайон (ММТ);

- «конструктор» из элементов сборного домостроения;

- репрезентативный центр как сакральное место праздничных шествий и манифестаций; • «платформа» — как второй уровень земли;

- транспортно-ориентированное планирование и транспортноориентированная жизнедеятельность (жизнь на колесах, мобильный горожанин) [Дембич, Закирова: 2020].

\section{Методологический подход}

Для того чтобы выделить на плане современный вернакулярный район центра был выбран метод глубинного интервью. В выборку вошли различные категории горожан Набережных Челнов, чтобы отобразить различия в восприятии центра разных социальных групп. Всем респондентам было предложено ответить на следующие основные вопросы: 


\section{ВСЕРОССИЙСКИЙ ИССЛЕДОВАТЕЛЬСКИЙ ФОРУМ СТУДЕНТОВ И УЧАЩИХСЯ}

Как давно вы проживаете в Набережных Челнах?

В каком районе вы проживаете?

Где по-вашему мнению сейчас расположен городской центр(-ы) в Набережных Челнах? (далее если вы выделили больше одного центра отвечайте по каждому из них)

Почему по-вашему мнению это место является центром?

На основании чего вы сделали такой вывод?

Какие услуги вы можете получить в центре?

Всегда ли это место было центром города? Если нет, то с какого момента оно им стало? В чем была причина?

Сколько времени вам нужно, чтобы добраться из дома до центра города? (обязательно указать тип вашего перемещения пешком/на машине/общественном транспорте).

Чем отличается выделенный вами современный центр города от района, где проживаете вы?

\section{Данные и результаты}

Собранные интервью:

Индира, 19 лет, проживает в Челнах с рождения

«Мой родной район города - посёлок элеваторная гора. Он достаточно удален от всех главных мест городской активности.... Вообще мне сложно, определить, где у нас расположен центр, я предполагаю, что на остановке «Центр», добираться на машине мне где-то минут 15-20. Там находится мэрия, но в основном именно из-за названия остановки я считаю это место центром. Рядом тут кониертный зал, можно и просто погулять - рядом находится площадь Азатльк. Я думаю, что раньше это место не было центром, потому что город начал строиться с ГЭСа, а только потом спустя время появился Новый Город - тогда, наверное, эта часть и стала центром. Центр отличается от моего района абсолютно всем, потому что я живу в частном секторе, но особенно архитектурой - там высотные дома, мосты, инфраструктура, которой нет у меня».

Лиля, 19 лет, живет в Челнах с самого рождения

«Я живу в Автозаводском районе, в 51 комплексе, если быть точной. $Я$ особо не понимаю, где у нас иентр, поэтому мне так сходу сложно определить. Думаю, всё-таки это площчадь Азатлык, там рядом мэрия же находится. Когда мэрию построили, тогда это место и стало иеетром. На 


\section{ВСЕРОССИЙСКИЙ ИССЛЕДОВАТЕЛЬСКИЙ ФОРУМ СТУДЕНТОВ И УЧАЩИХСЯ}

общественном транспорте мне ехать до туда минут 15, на машине - 10. Центр отличается от моего района тем, что у меня нет различных торговых центров, кафе, также мест, где можно выйти с семьей погулять».

Разия, 19 лет, проживает в городе с рождения

«Я живу в поселке Сидоровка. Он находится около вокзала, обычно данный район называют началом города. По моему мнению цеентр города Набережные Челны находится там, где расположена площуадь Азатльк, торговый центр, а также заведения, где можно позавтракать, отобедать или же поужинать. На площуади можно и погулять, и сходить за покупками, также недалеко находится набережная, что является огромным плюсом. В изентре обычно проводят разные мероприятия. К примеру, всем известный праздник Новый год, для которого в городе, в разных районах ставят ёлку, и данная площуадь не исключение. Ёлка, которая находится на площуади отличается тем, что она выше, ярче и по моему мнению красивее. Также на площуади заливают каток, на который приходят очень много людей. Я считаю, что данное место было и будет центром города, так как оно не теряет свою актуальность для разных возрастов. До центра города Набережные Челны я добираюсь 40 минут, если еду на маршрутке. Но время, чтобы добраться до ичентра на машине понадобится 30 минут. Мой район и центр города отличается тем, что в моем районе нет торгового ичентра, нет разных кафешек, не так много заведений, куда можно сходить за покупками, то есть за товарами для дома или же магазины одежды, в основном магазины с продуктами. В моем поселке Сидоровка в основном старые здания, но со временем я думаю, что он станет обновленным, то есть появятся новые здания, которые не будут лишним для каждого проживающего человека в городе Набережние Челныл

Диляра, 19 лет, живет в Челнах с рождения

«Я проживаю в Автозаводском районе. Я считаю, что чентр нашего города находится на площуади Азатльк, так как рядом с площуадью находится Мэрия города, большая часть городских мероприятий проводится именно на этой площзади. Рядом с площзадью находится торговый изентр Палитра, в котором есть множество магазинов, салонов красота, изветочный магазин, аптека, кафе, концертный зал имени Сары Садыковой, поэтому получит можно множество услуг. Я думаю, что это место всегда было изентром города.На машине дорога занимает 10 минут, на общественном транспорте 


\section{ВСЕРОССИЙСКИЙ ИССЛЕДОВАТЕЛЬСКИЙ ФОРУМ СТУДЕНТОВ И УЧАЩИХСЯ}

чуть больще - минут 15, пешком минут 25. Рядом с площуадью Азатлькк находится вся администрация города, в моем районе ее нет»

Ксения 19 лет, в Челнах с рождения

«Я живу достаточно близко к изентру, на проспекте Хасана Туфана. Городским изентром считаю площуадь Азатльк. Считаю, что данная площуадь, является одной из главных площуадей Набережных Челнов, так как она хорошо благоустроена, есть фонтан, смотровая площуадка амфитеатр. Более того, что не мало важно, там расположена мэрия, и есть концертный зал. Рядом с площцадью расположен торговый цуентр, в котором есть множество различных магазинов и кафе, а также спортивный клуб. По-моему мнение, данное местоположение даёт возможность каждому человеку найти чем ему заняться. Помимо этого на данной площуадок всегда проводят праздники с развлекательной интересной программой для всех желающих, а на Новый год именно оттуда стреляют салют. Для меня площадь Азатльк всегда была центром - пешком мне до нее 7 минут. В моем районе расположень многоквартирные дома, где нет особо привлекательных мест для прогулок»

Наташа, 19 лет, живет в городе с рождения

«Живу на набережночелнинском проспекте, в 62 комплексе. Городской цүентр - район от тюбетейки до мэрии, потому что там много заведений, жильх комплексов и то. Там есть услуги - от покупки товаров различной необходимости и происхождения до развлекательных услуг-мне кажется, оно всегда было ичентром, по времени добираться - минут 15-40, смотря на чем. обычно на марирутке - 15 минут. Это цуентр, потому что там есть площуадь, где можно гулять»

Арина, 19 лет, живет в городе с рождения

Я живу в 42 комплексе. Центр, по-моему, расположен возле площуади Азатльк, там и мэрия, и ти, и остановка называется «Центр». Я думаю, площзадь всегда была изентром города. Мой район находится прям в цчентре».

Гульнара, 49 лет, живет в городе с рождения по настоящее время

«Я жниу в Центральном районе. Центр для меня понятие, которое зависит от времени года. Зимой - это площуадь Азатльк перед мэрией города. Летом для жителей Нового города ичентром становится бульвар Энтузиастов (дежавю), Парк Победьл. Для жителей старой части города - улица цеентральная с благоустроенной набережной. Для меня место является цчентром, если там проводятся культурно-массовые мероприятия. В иентре я могу получить развлекательные услуги. Бульвар энтузиастов стал ияентром с 
момента благоустройства города - там начали проводится различные мероприятия. Центр по сравнению с моим районом более благоустроенньй, более многолюдный, мой же район спальный».

Регина, 36 лет, проживает в Челнах с 2002 года

«Я живу в Автозаводском районе. По моему мнению, в городе сейчас 2 центтра: это площуадь Азатльк, расположенная в Центральном районе около здания мэрии, второй центр - это парк победы. В этих районах благоустроенно, проводятся праздничные мероприятия, много парков. В цуентре есть торговые центры (кинотеатры, магазины, прогулка в парке). На мой взгляд этот район всегда был чуентром. Центр города отличается многолюдностью, благоустроенностью, наличием развлекательных ичентров».

Регина, 19 лет, живет в Челнах с рождения

«Я живу в загородном доме, в поселке Большая Шильна. На мой взгляд, городской центр расположен на проспекте мира (ТЦ Палитра). Это место изентр, потому что там всегда много людей и развлекательных игр. Я думаю, что Палитра всегда была чзентром города».

Айгуль, 34 года, живет в Челнах с рождения

«Я живу в районе Автозаводский. Ну я могу вылелить 4 условных иентра города: это мэрия, парк победы, площуадь Азатльк и Бульвар Энтузиастов. Там часто проводят мероприятия и концерть, то есть в основном там развлекательная функция. На моей памяти эти места всегда были ијентрами, с моего рождения - там большее количество транспорта и людей, сама я проживаю в спальном районе без проходньх улицу».

Катя, 31 год. Живет в городе 29 лет

«Я живу в Автозаводском районе, изентром города я считаю район от медгородка до 6 комплекса - это наиболее частое и удобное место встречи для всех районов, здесь можно получить практически все услуги. Это всегда для меня было центром города, тут есть торговые центры, места для прогулок, много общепита, кинотеатры и так далее».

Алия, 40 лет, живет в Челнах с 2008 года

«Живу в районе ЗЯБ, чентром города для меня является Санрайз-Сити, там можно получить много развлекательных, косметологических, потребительских услуг. Отличие от моего района состоит в том, что у меня мало развлечений для семей с детьми».

Ангелина, 19 лет, живет в Челнах с рождения 
«Думаю, что чуентр города сейчас приходится на Медгородок, где Торговый Квартал. Считаю так, потому что очень много людей встречаются именно там и по площуади города это +\- центр. Там есть и больница, $и$ торговый центр и несколько остановок для разного вида общественного транспорта, а также спортивные зальл. Думаю, не всегда это место было центтром. Площуадь города с каждыл годом росла. Может быть, изентом раньие был район, где сейчас находится вечный огонь. Все изменилось, полагаю в 2000-е. На машине до Торгового квартала примерно 15 минут. Центр города сильно отличается от моего района, потому что там больше удобств общественного транспорта, все его виды представлены там. Так же много магазинов, где можно найти все: от хозяйственных вещуей до одежды. Для машин там тоже много чего, заправки и сервисные цуентры. Спортзаль и центтры дошкольного развития».

Илья, 19 лет, живет в Челнах с рождения

«Проживал в Челнах до 18 лет, уехал в Ижевск на учебу, приезжаю к семье на праздники и выходные.

Проживаю в Новом городе, иентральном районе Набережных Челнов.

Я считаю, что городскими цуентрами Набережных Челнов можно считать торговый квартал и проспект Мира в районе торгового чуентра "Омега". Я считаю, что эти места можно назвать центром города, т.к. там можно найти многие необходимые вещзи, отдохнуть с друзьями, провести досуг и т.д. Подобный вывод я делаю на основании своего личного опыта. Не могу сказать, всегда ли это место было центром города. Около 15-20 минут пешком.В моем комплексе меньше мест, где можно весело провести досуг с друзьями, сложнее найти необходимые вещчи, например одежду, обувь и т.п.».

Рафис, 49 лет, проживает в Челнах с рождения

«Я живу в Центральном районе. Сейчас понятие иентра города размыто. Вся жизнь городская, суета крутится вокруг торговых иентров, а их в городе много и выделить какой-то один не представляется возможным. Но лично я связываю центр города с его административным центром, $а$ именно мэрией. В этом месте сосредоточена вся городская власть. Здесь принимаются решения, влияющие на жизнь города. В центре я могу получить все услуги. Мэрия всегда была цуентром города - это ещуё и исторический цуентр города. От моего района центр особо не отличается, может быть, если только там больше открытого пространства».

Татьяна, 20 лет 
«B Челнах проживаю с 6 лет, в иентральном районе. По-моему, сейчас центры города расположены вокруг мэрии, сама площадь Азатлькк, бульвар Энтузиастов, в районе торгового квартала, ледового двориа, набережной, так как там наибольшие скопления людей и сосредоточены все заведения и организачии необходимые человеку: больнииы, магазины, различные кафе и рестораны и т.д.

Я думаю, что эти места не всегда были центром города, не считая площади Азатльк. Скорее всего, эти места стали центром города, когда там начали собираться большие массы молодых людей, и начали заниматься облагораживанием территорий.

Чтобы добраться до перечисленных иеентров, мне нужно от 5 до 30 минут пешком. Ничем не отличается, так как я живу в одном их этих иентров».

Ответы других респондентов не были включены в основной текст, ими были также были выделены Бульвар Энтузиастов, Площадь Азатлык как центр города.

Количественные данные проведенных интервью представлены в диаграммах ниже. Также на основе интервью были выделены предполагаемые зоны актуальных городских центров.

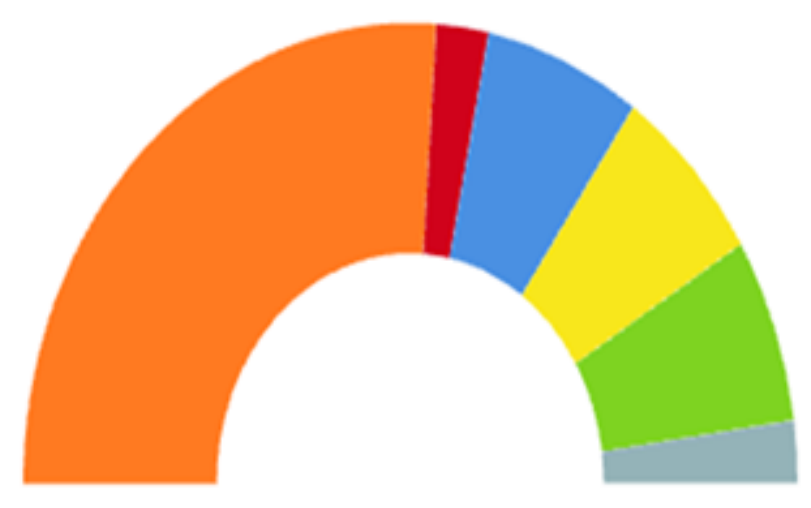

Азатлык (52.17\%) - Санрайз сити (4.35\%)

Бульвар Энтузиастов (13.04\%)

проспект Мира (13.04\%) П Парк победы (13.04\%)

Центральная Набережная (4.35\%)

Рис. 1. Распределение ответов всех респондентов 


\section{ВСЕРОССИЙСКИЙ ИССЛЕДОВАТЕЛЬСКИЙ ФОРУМ

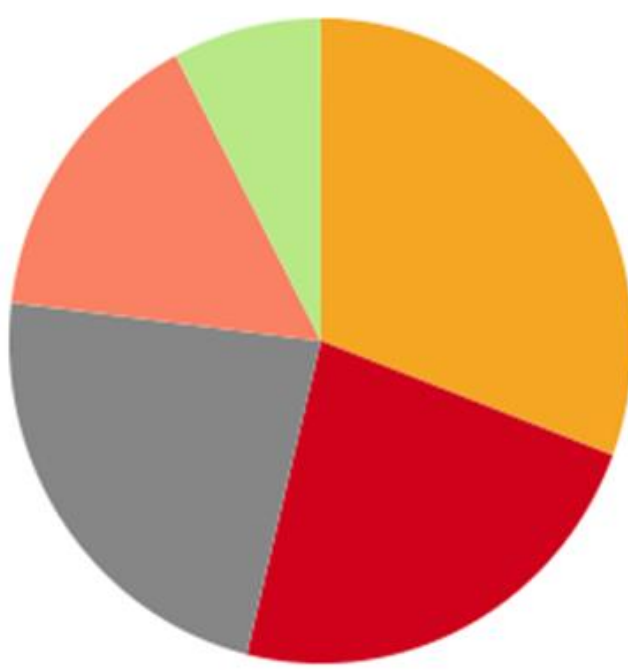

Азатлык (30.77\%) Бульвар Энтузиастов (23.08\%)

Проспект Мира (23.08\%) П Парк Победы (15.38\%)

Санрайз сити (7.69\%)

Рис. 2. Распределение ответов от респондентов младше 20 лет

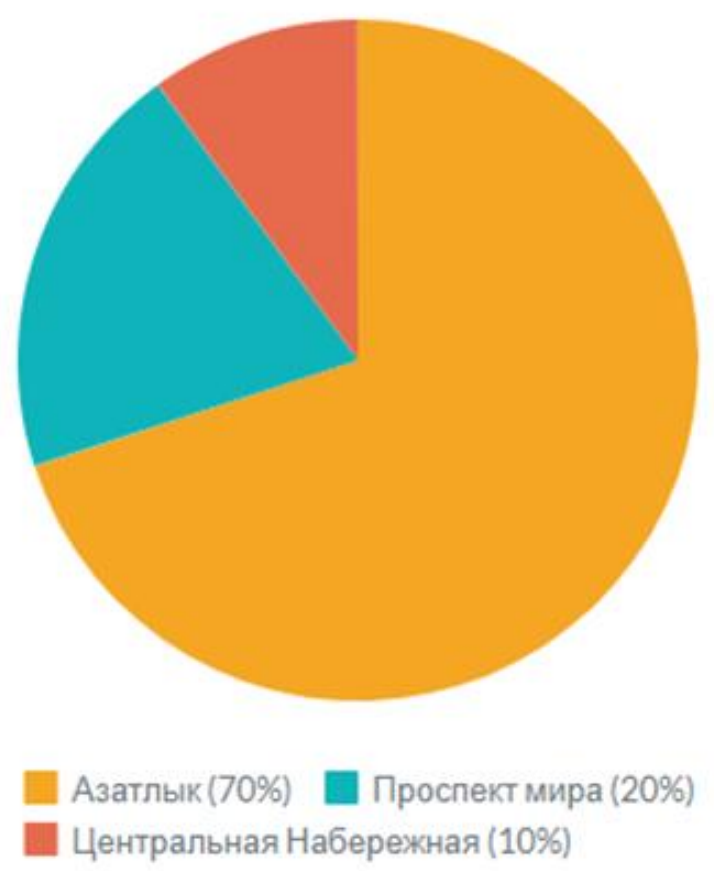

Рис. 3. Распределение ответов от респондентов 20+ 


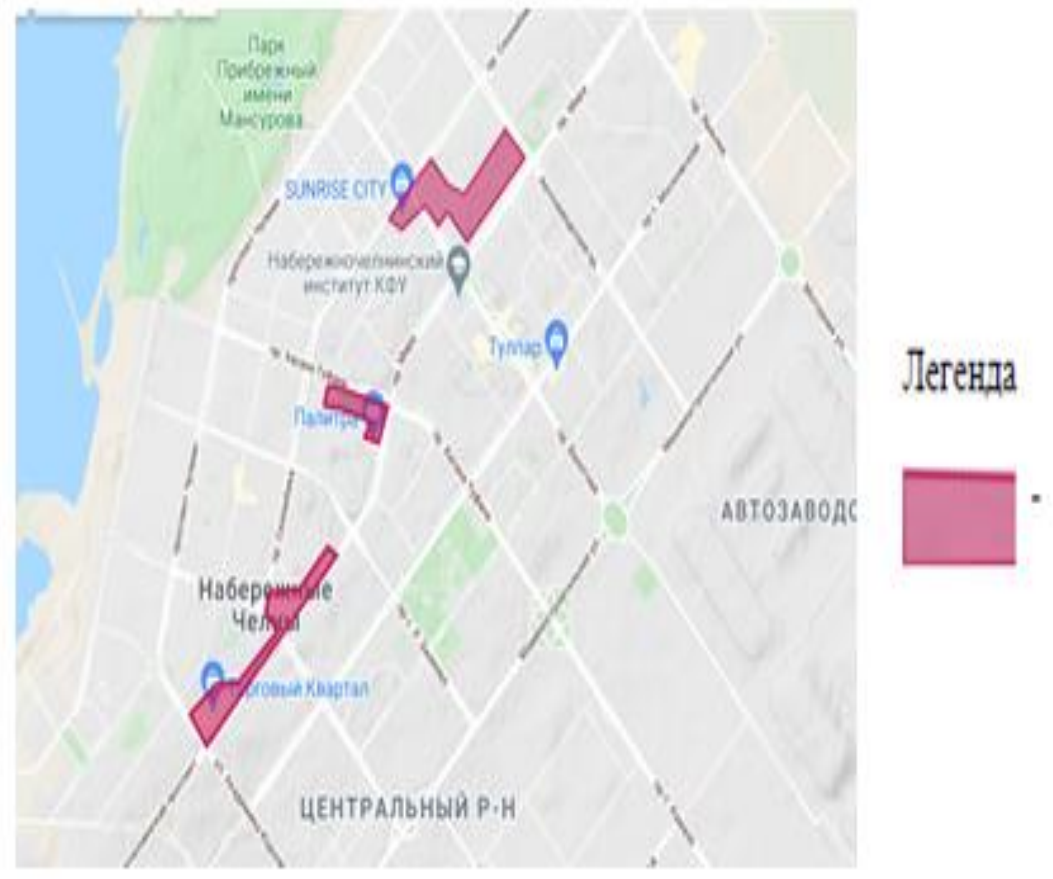

территорні:

предпотагаемых пентров

\section{Рис. 4. Карта предполагаемых центров}

\section{Обсуждение}

В процессе интервью многие затруднялись назвать центр своего собственного города - причина в том, что пространство Челнов не имеет чёткого функционального деления и исторически сложившегося центра: весь город преимущественно состоит из однотипной панельной жилой застройки, каждый комплекс которой обеспечен одними и теми же услугами - типичная черта российского моногорода, спланированного для обеспечения жилым фондом работников градообразующего предприятия. Проблема состоит также в том, что город застраивался неодновременно: сначала появились районы ЗЯБ и ГЭС, а потом уже только Новый город. Это привело к двойственности в выделении центра для старой и новой части города: это видно даже в названии остановок общественного транспорта: «Центральная» находится на ГЭСе, а «Центр» - в Новом городе.

До появления крупных торговых центров не было необходимости выезжать не в «свой» магазин - доминантой в городском пространстве служила мэрия, выполняющая уникальные административные функции. Поэтому для большинства опрошенных важнейшим маркером центра являлась городская администрация - это традиционный в контексте Челнов подход к осмыслению 


\section{ВСЕРОССИЙСКИЙ ИССЛЕДОВАТЕЛЬСКИЙ ФОРУМ СТУДЕНТОВ И УЧАЩИХСЯ}

центра. Аттрактивный элемент этой зоны также усиливает торговый центр «Палитра». Многие респонденты при описании отличности, уникальности центра отталкивались от расположения там главной площади, что не случайно: на генеральном плане Набережных Челнов главная площадь заявлялась как центральная - место для проведений демонстраций, шествий и городских праздников. Территорию перед мэрией, включающую в себя Палитру и площадь Азатлык, таким образом можно назвать супер-центром, вернакулярным районом, где наиболее ярко выражена оппозиция к периферии.

Также любопытно, что для жителей наиболее отдаленных районов вернакулярный центр имеет более большую площадь. Например, для Разии, которая живёт в посёлке Сидоровка, центр включает в себя не только площадь Азатлык, но и территорию Центральной набережной. Группа респондентов 20+ выделяет более разнообразные центры, чем группа моложе 20 лет.

Другой выявленный среди горожан подход к выявлению центра - это концентрация коммерческих и развлекательных функций на территории. Причём эти субцентры начали появляться со строительством крупных ТЦ в городе и стали конкурировать со сложившимся супер-центром.

Также многие отталкивались от топонимов - остановка «Ценртальная», «Центр» и др.

\section{Выводы}

На данный момент в Челнах невозможно выделить пространственноцелостный единый центр. Функции центра разделены между территориями, которые находятся в районе Нового города - это ТЦ «Торговый Квартал», «Палитра», «Санрайз-сити», площадь Азатлык и Парк Победы. Каждая из этих зон имеет частичный набор функций центра. Центральные зоны имеют возможность дополнять друг друга, так как находятся на близком расстоянии друг от друга.

\section{Список литературы}

1. Бегеза С. Е. О целостности городской среды // Вестник ИрГТУ. - 2014. - № 8 (91). C. 82-85.

2. Гашенко А. Е. Семантика целостности архитектурноградостроительной морфологии городского центра // Праксема. Проблемы визуальной семиотики. - 2016. - №. 2. - С. 82-96. 
3. Дембич А. А., Закирова Ю. А. Проблемы пространственного планирования г. Набережные Челны в постсоветский период // Вестник МГСУ. - 2020. - Т. 15. - №. 5.

4. Маслова А. Н. Моногорода в России: проблемы и решения // Контуры глобальных трансформаций: политика, экономика, право. 2011. №5. URL: https://cyberleninka.ru/article/n/monogoroda-v-rossii-problemy-i-resheniya (дата обращения: 15.10.2021).

5. Развитие моногородов России / В. Е. Лепский, А. В. Молодцов, В. Г. Попов [и др.] ; Под редакцией Ильиной И. Н.. - Москва : Финансовый университет при Правительстве Российской Федерации (Финансовый университет), 2013. - 168 с. - ISBN 9785794210361.

(С Л.Р. Гильмутдинова, 2021 